\title{
Erratum to: Internally consistent geothermometers for garnet peridotites and pyroxenites
}

\author{
Paolo Nimis • Herman Grütter
}

Published online: 3 December 2009

(C) Springer-Verlag 2009

\section{Erratum to: Contrib Mineral Petrol}

\section{DOI 10.1007/s00410-009-0455-9}

Owing to an unfortunate oversight at the proof correction stage, the updated versions of certain figures supplied by the author were not inserted in the article. The spreadsheet used for the uncorrected figures contained a small error in the $P_{\mathrm{NG85}}$ expression. The correct versions of Figs. 2, 3, 4, $5,6,7$ and 10,11,12,13,14 are shown here together with their legends.

Moreover, Fig. 1 in the Electronic Supplementary Material has also been updated.

The online version of the original article can be found under doi:10.1007/s00410-009-0455-9.

P. Nimis $(\bowtie)$

Dipartimento di Geoscienze, Università di Padova,

via Giotto 1, 35137 Padua, Italy

e-mail: paolo.nimis@unipd.it

P. Nimis

CNR-IGG, Padua, Italy

H. Grütter

BHP Billiton World Exploration Inc,

\#800 Four Bentall, 1055 Dunsmuir Street,

Vancouver, BC V7X 1L2, Canada 
Fig. $2 P-T$ estimates for graphite-bearing (solid circles) and diamond-bearing (open diamonds) lherzolites using different versions of the Al-inOpx barometer $\left(P_{\mathrm{BKN}}\right.$ : Brey and Köhler 1990; $P_{\mathrm{BBG} 08}$ : Brey et al. 2008; $P_{\mathrm{NG} 85}$ : Nickel and Green 1985; $P_{\text {NG85mod Taylor98: }}$ $P_{\mathrm{NG85}}$ with $X_{\mathrm{Al}}^{\mathrm{M} 1}$ calculated as recommended by Taylor 1998; $P_{\mathrm{NG} 85 \bmod \text { Carswell91 }}: P_{\mathrm{NG} 85}$ with $X_{\mathrm{Al}}^{\mathrm{M} 1}$ calculated as recommended by Carswell 1991; $P_{\text {SI08 }}$ : Simakov 2008). Tie-lines connect estimates obtained using different published analyses of the same sample. The NG85 version and its modification by Carswell (1991) are the most consistent with diamond and graphite stability. The diamond-graphite boundary was calculated from thermodynamic properties of carbon after Chatterjee (1991) and is in excellent agreement with the experiments of Kennedy and Kennedy (1977) at $T=1,100-1,600^{\circ} \mathrm{C}$
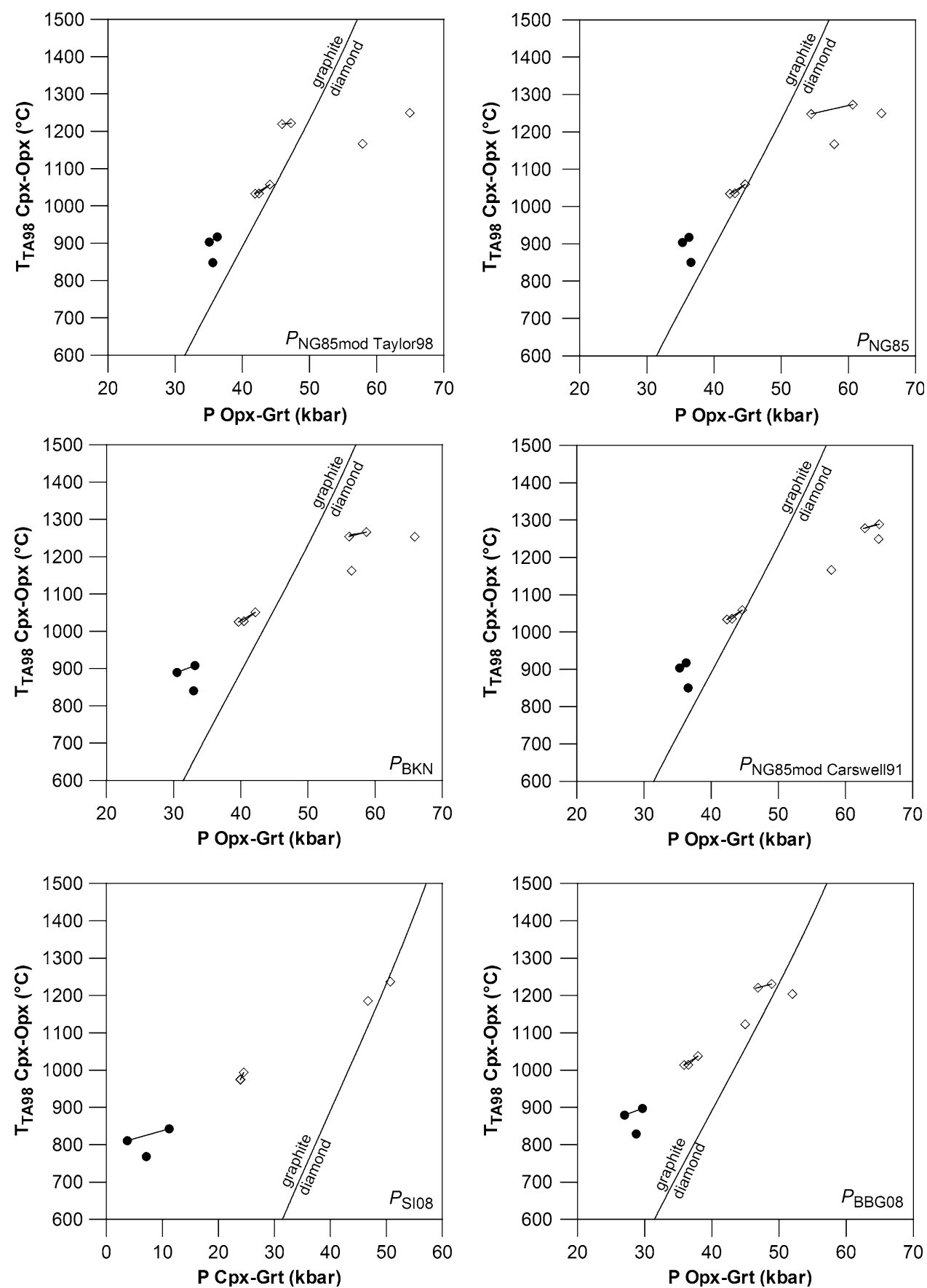

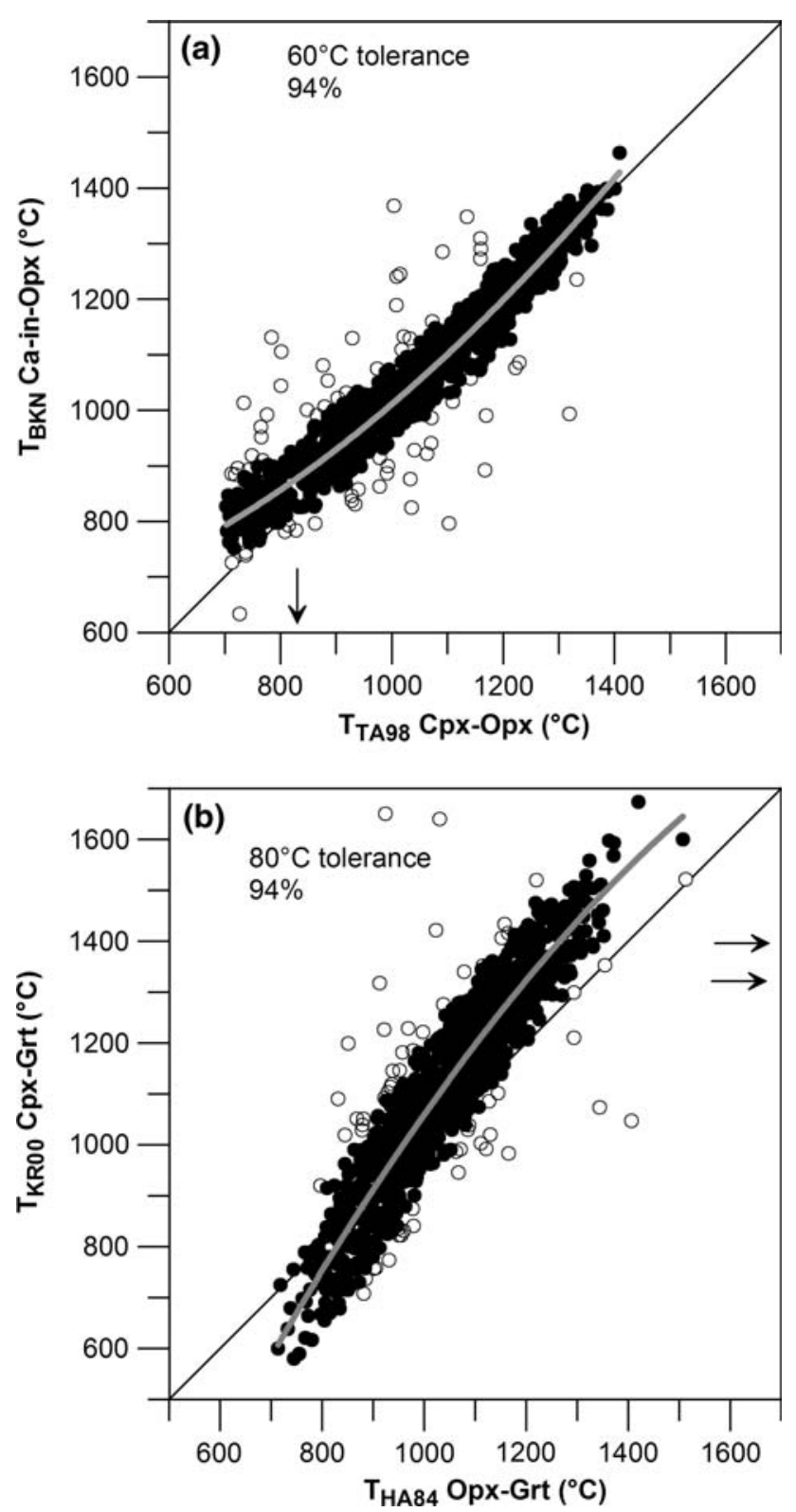

Fig. 3 a Correlation between $T_{\mathrm{BKN}}^{\mathrm{Ca}-\mathrm{in}-\mathrm{Opx}}$ and $T_{\mathrm{TA} 98}^{\mathrm{Cpx}-\mathrm{Opx}}$ calculated at $P$ given by the combination of NG85 barometer and TA98 thermometer. Points more than $60^{\circ} \mathrm{C}$ off the correlation line (open circles) were discarded. b Correlation between $T_{\mathrm{KR} 00}^{\mathrm{Cpx}-\mathrm{Grt}}$ and $T_{\mathrm{HA} 84}^{\mathrm{Opx}-\mathrm{Grt}}$ for samples selected according to a, calculated at same $P$ as above. Arrows point to outliers off the plot field. Points more than $80^{\circ} \mathrm{C}$ off the correlation line (open circles) were discarded. Source of data is given in the online supplementary material 
Fig. 4 Relationships between $T_{\mathrm{HA} 84}^{\mathrm{Opx}-\mathrm{Grt}}-T_{\mathrm{TA} 98}^{\mathrm{Cpx}-\mathrm{Opx}}$ and temperature for representative and well-known xenolith localities. Circles peridotites, triangles pyroxenites. Open symbols indicate points falling off the main linear trends, which were excluded from the database. The complete set of locality plots is given in the Supplementary Fig. 1. See text for further explanation
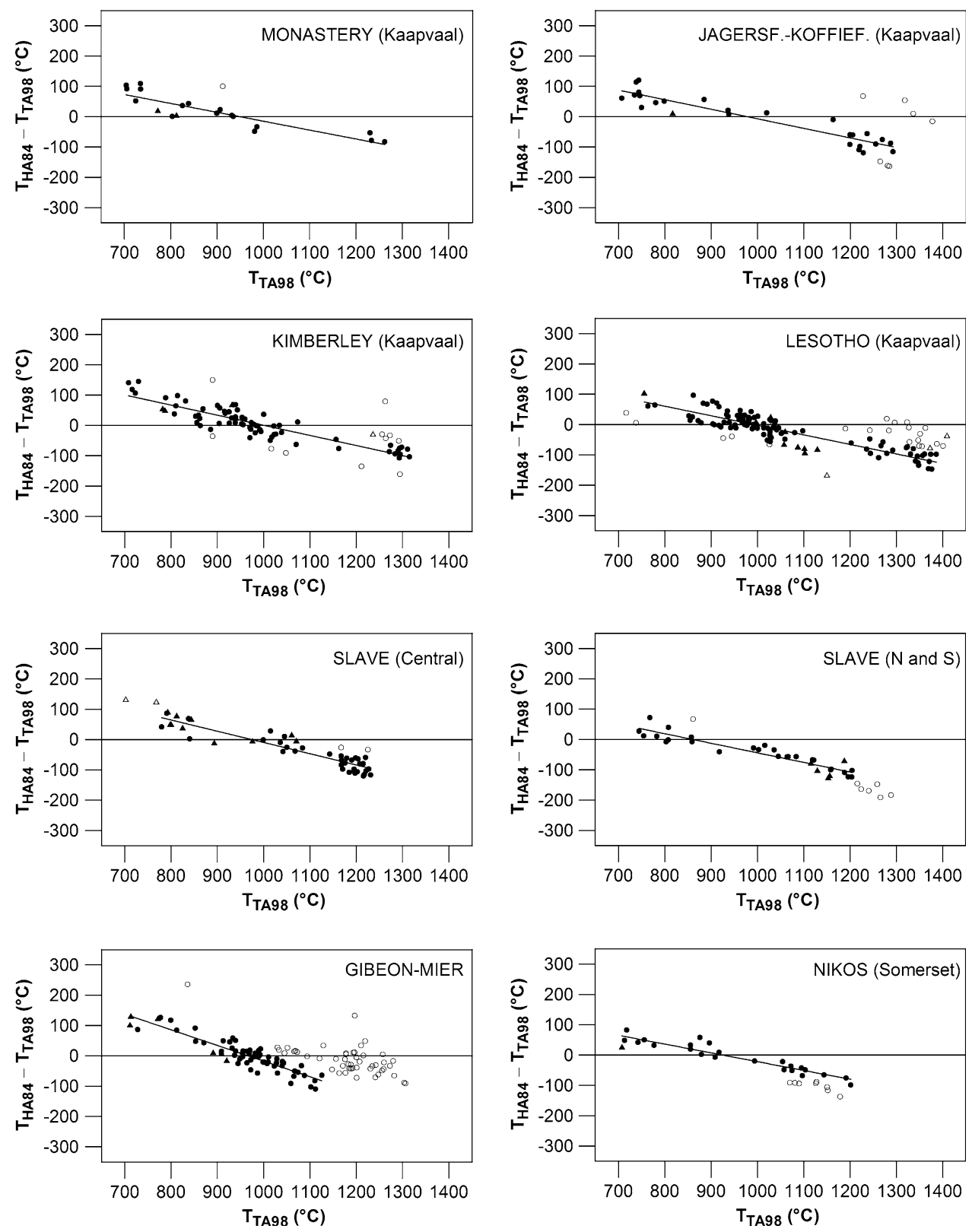

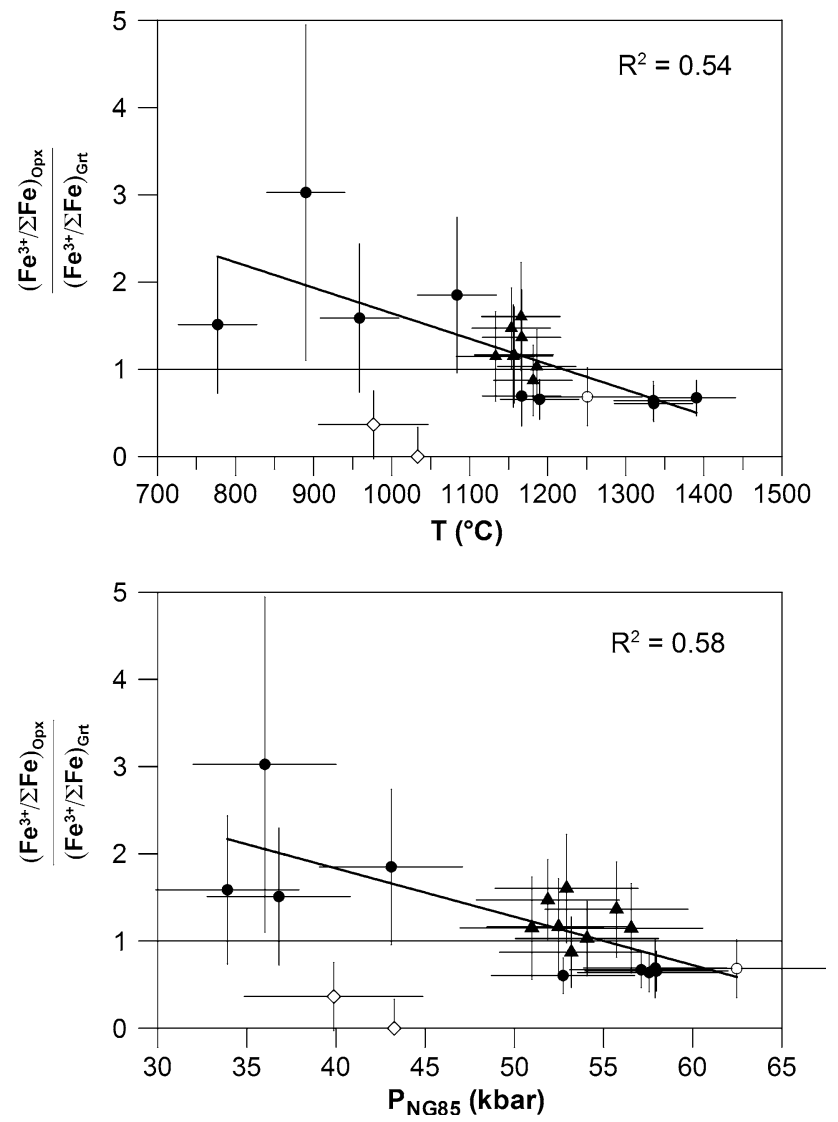

Fig. 5 Variation of $\frac{\left(\mathrm{Fe}^{3+} / \Sigma \mathrm{Fe}\right)_{\mathrm{Opx}}}{\left(\mathrm{Fe}^{3+} / \Sigma \mathrm{Fe}\right)_{\mathrm{Crt}}}$ ratio versus $T$ and $P$ in mantle xenoliths of various provenance, calculated using Mössbauer data for garnet, clinopyroxene and, where available, orthopyroxene and Canil and O'Neill's (1996) orthopyroxene-clinopyroxene $\mathrm{Fe}^{3+}$ partitioning systematics. For clinopyroxene-bearing samples (solid symbols), only samples satisfying $T_{\mathrm{TA} 98}^{\mathrm{CPx}-\mathrm{Opx}}$ versus $T_{\mathrm{BKN}}^{\mathrm{Ca}-\mathrm{in}-\mathrm{Opx}}$ relationships discussed in the text were considered and $T$ was estimated with the TA98 thermometer $\left( \pm 50^{\circ} \mathrm{C}\right.$ and $\pm 4 \mathrm{kbar}$ uncertainties were assumed); for clinopyroxene-free samples (open symbols), $T$ was estimated with the new orthopyroxene-garnet thermometer (see Eq. $4 ; \pm 70^{\circ} \mathrm{C}$ and \pm 5 kbar uncertainties were assumed). Conservative uncertainties on $\frac{\left(\mathrm{Fe}^{3+} / \Sigma \mathrm{Fe}\right)_{\mathrm{px}}}{\left(\mathrm{Fe}^{3+} / \Sigma \mathrm{Fe}\right)_{\mathrm{Grt}}}$ were calculated assuming an absolute error of 0.02 on garnet and orthopyroxene $\mathrm{Fe}^{3+} / \Sigma \mathrm{Fe}$ data and normal error propagation. Source of data: circles Canil and O'Neill (1996); triangles Woodland and Peltonen (1999); diamond McCammon et al. (2001; garnet core analyses). McCammon et al's (2001) data referred to strongly zoned, metasomatized samples that fell off the general trends and were excluded from regressions

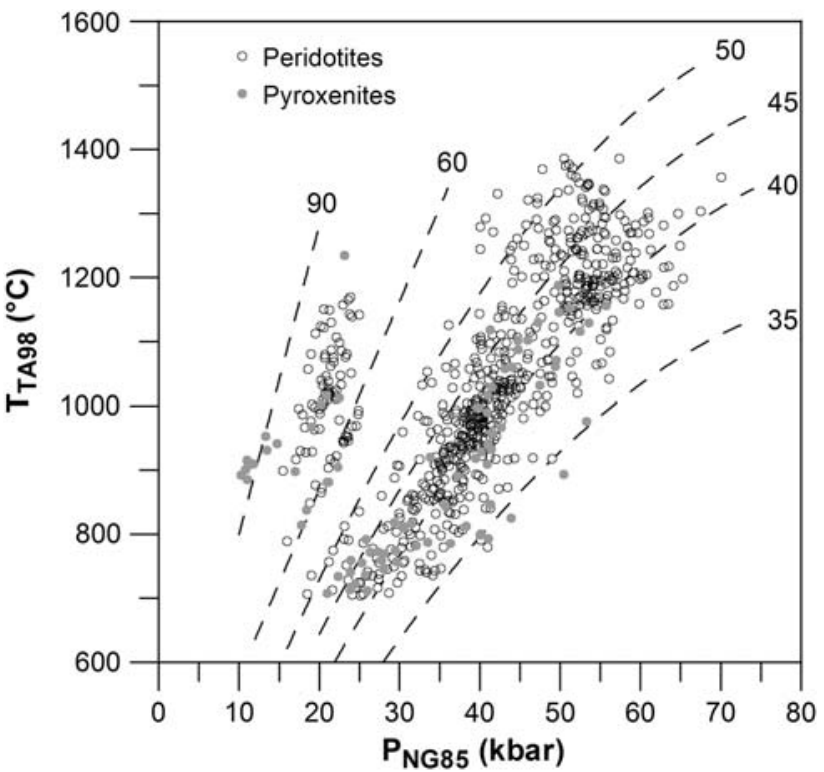

Fig. $6 P-T$ conditions for the selected well-equilibrated mantle xenoliths, calculated by the combination of NG85 Al-in-Opx barometer and TA98 two-pyroxene thermometer. Reference geotherms after Pollack and Chapman (1977) 


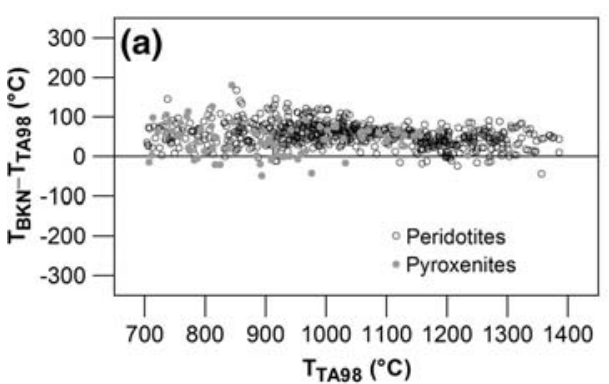

Fig. 7 Discrepancies between $T_{\mathrm{BKN}}^{\mathrm{Cpx}-\mathrm{Opx}}$ and $T_{\mathrm{TA98}}^{\mathrm{Cpx}-\mathrm{Opx}}$ for well-equilibrated mantle xenoliths, calculated at $P$ given by the combination of NG85 Al-in-Opx barometer and TA98 two-pyroxene thermometer, plotted against (a) $T_{\mathrm{TA} 98}^{\mathrm{Cpx}-\mathrm{Opx}}$ and (b) $\mathrm{Na}_{\mathrm{Cpx}}$. Arrows indicate the

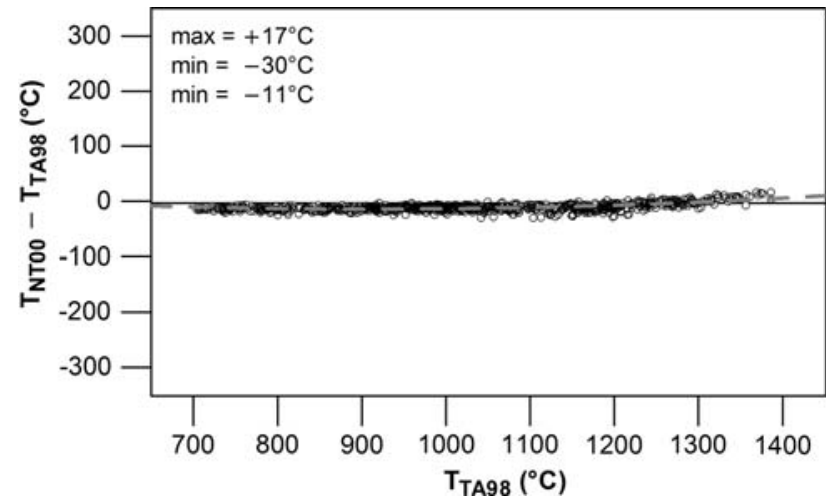

Fig. 10 Correlation between $T_{\mathrm{NT} 00}^{\mathrm{en}-\mathrm{in}-\mathrm{Cpx}}$ and $T_{\mathrm{TA}}^{\mathrm{Cpx}-\mathrm{Opx}}$ calculated at $P$ given by the combination of NG85 Al-in-Opx barometer and TA98 thermometer, for well-equilibrated mantle xenoliths. A polynomial best-fit curve is shown as a dashed line

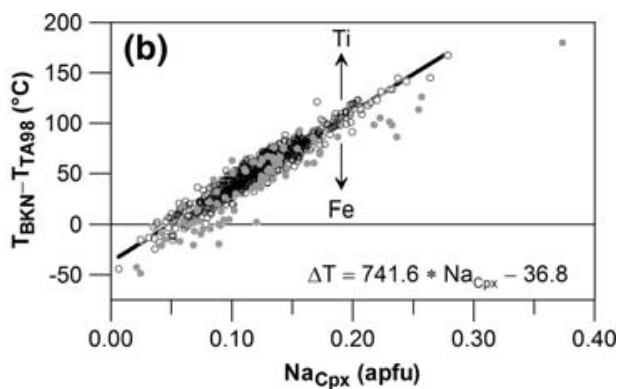

additional minor effects of increasing $\mathrm{Fe}_{\mathrm{Cpx}}$ and $\mathrm{Ti}_{\mathrm{Cpx}}$ on these discrepancies. The regression line does not include the pyroxenite samples, for which the $\mathrm{Fe}-\mathrm{Ti}$ effects are the most evident

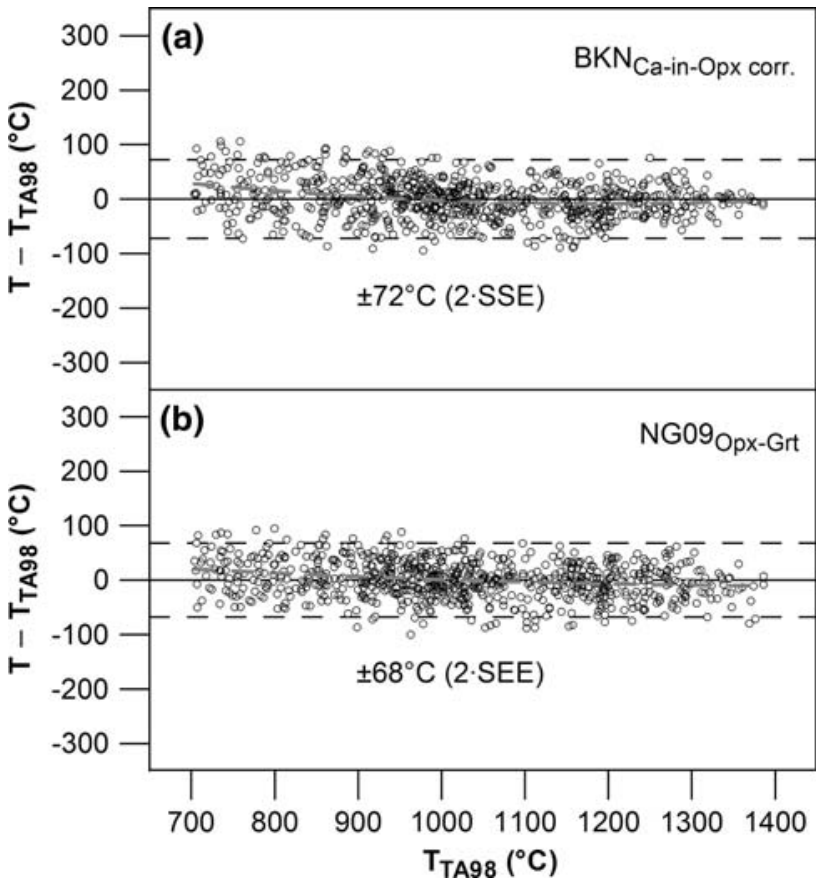

Fig. 11 Calibration residuals of (a) the corrected Ca-in-Opx thermometer (Eq. 1) and of (b) the new Opx-Grt thermometer (NG09; Eq. 4). Black dashed lines are at two standard errors of estimate. Polynomial best-fit curves (halftone dashed lines) evidence the slight residual positive bias at very low $T$ (ca. $30^{\circ} \mathrm{C}$ and $20^{\circ} \mathrm{C}$ at $T_{\mathrm{TA98}}^{\mathrm{Cpx}-\mathrm{Opx}}=700^{\circ} \mathrm{C}$, respectively) 
Fig. 12 Difference between temperatures calculated with the new Opx-Grt thermometer (NG09; Eq. 4) and TA98, for representative and well-known xenolith localities (compare with Fig. 4). Dashed lines are at 2 standard errors of estimate $\left( \pm 70^{\circ} \mathrm{C}\right)$. Relationships of $T_{\mathrm{NG} 99}^{\text {Opx-Grt }}-T_{\mathrm{TA} 98}^{\mathrm{Cpx}-\mathrm{Opx}}$ with temperature are discussed in the text. Symbols are as in Fig. 4.

The complete set of locality plots is given in the supplementary Fig. 1
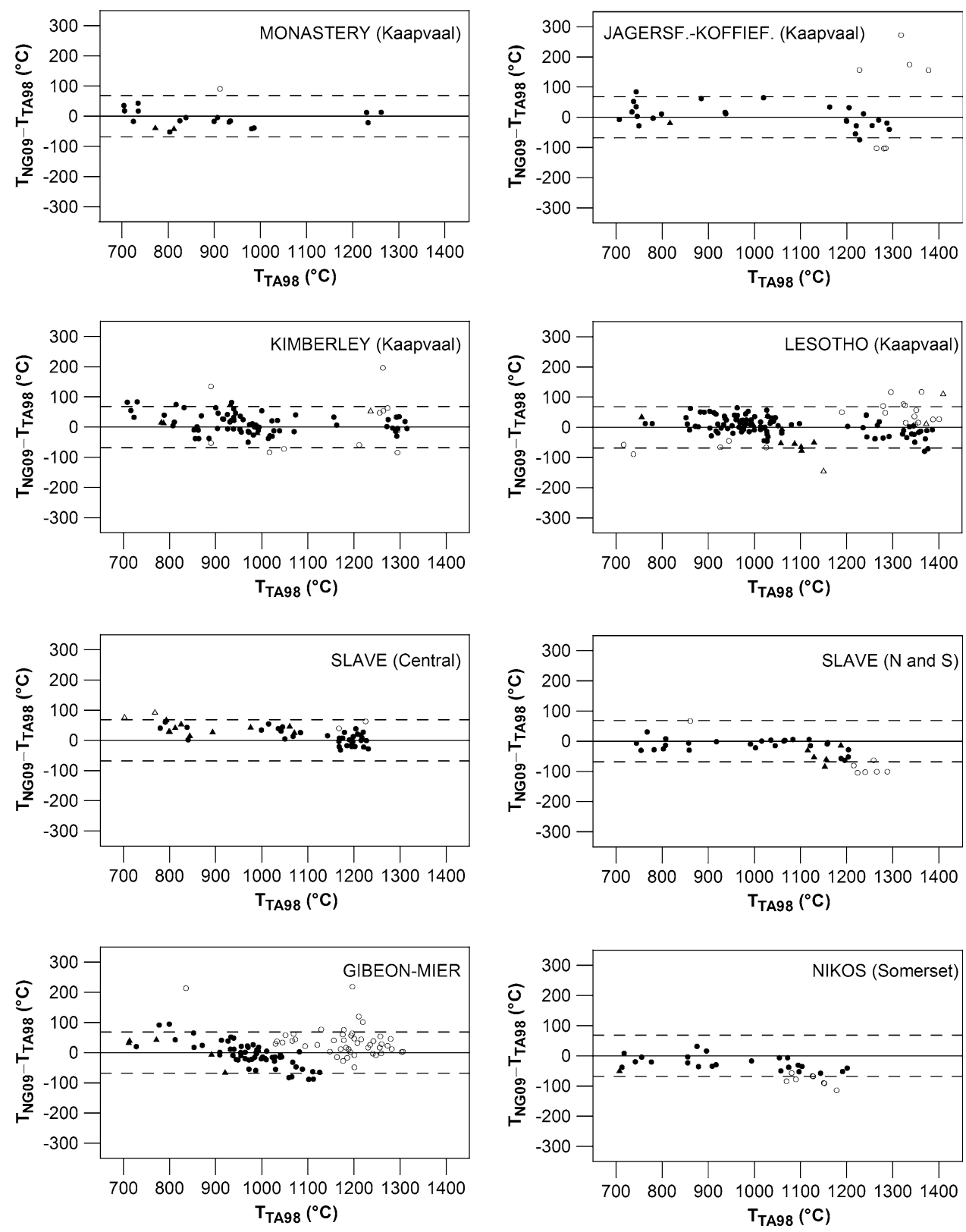


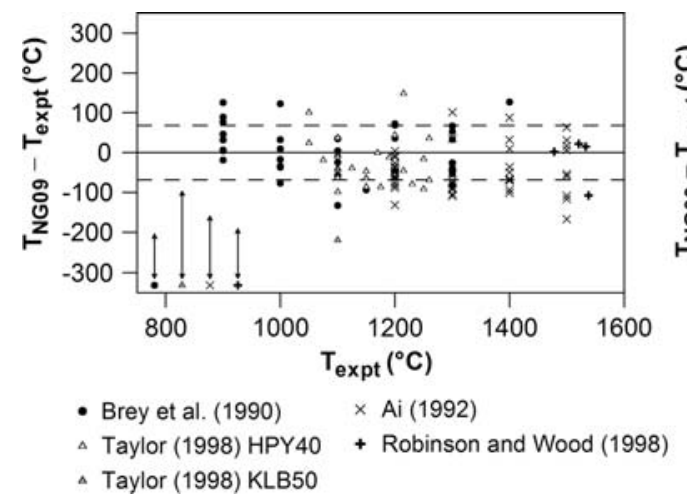

Fig. 13 Difference between temperatures calculated with the new Opx-Grt thermometer (NG09; Eq. 4) and experimental temperatures for experiments in natural peridotite systems run in graphite (Ai 1992; Taylor 1998; Robinson and Wood 1998) or olivine capsules (Brey et al. 1990). The KLB50 series by Taylor (1998) used a carbonate flux. Dashed lines are at 2 standard errors of estimate (SEE) of the

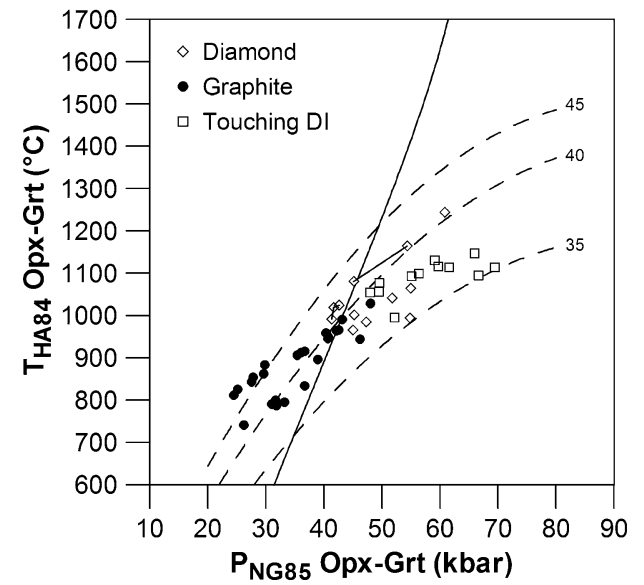

Fig. $14 P-T$ estimates for graphite- or diamond-bearing peridotites and pyroxenites and touching orthopyroxene-garnet inclusions in diamonds, obtained using the HA84 (Harley 1984) and NG09 (Eq. 4 of this work) orthopyroxene-garnet thermometers in combination with the NG85 barometer. Tie-lines connect estimates obtained using different published analyses of the same sample. Most $P_{\mathrm{NG} 85}-T_{\mathrm{NG} 09}$ points plot close to the $40 \mathrm{~mW} / \mathrm{m}^{2}$ geotherm of Pollack and Chapman (1977), whereas $P_{\mathrm{NG} 85}-T_{\mathrm{HA} 84}$ points crosscut theoretical geotherms. Two aberrant diamond-bearing samples showed strongly diverging orthopyroxene-garnet and two-pyroxene temperatures $\left(\Delta T=80-230^{\circ} \mathrm{C}\right)$,

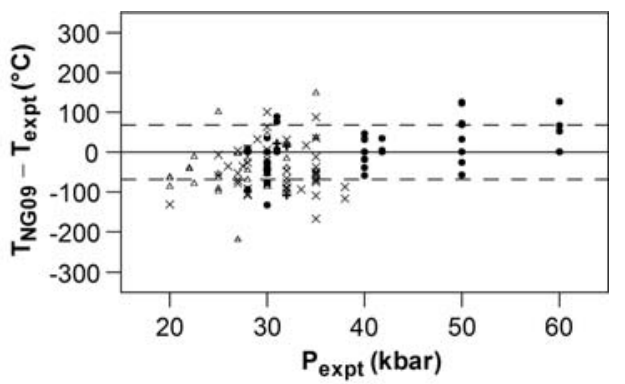

thermometer calibration. Double arrows indicate maximum variations of $T_{\mathrm{NG} 09}^{\mathrm{Opx}-\mathrm{Grt}}-T_{\mathrm{TA98}}^{\mathrm{Cpx}-\mathrm{Opx}}$ between experiments at the same $P$ and $T$ (within $\pm 5^{\circ} \mathrm{C}$ ) for each experimental data set, and give an idea of the possible effect of experimental uncertainties on calculated $T$. All experimental temperatures are reproduced to within 2 SEE if such uncertainties are considered

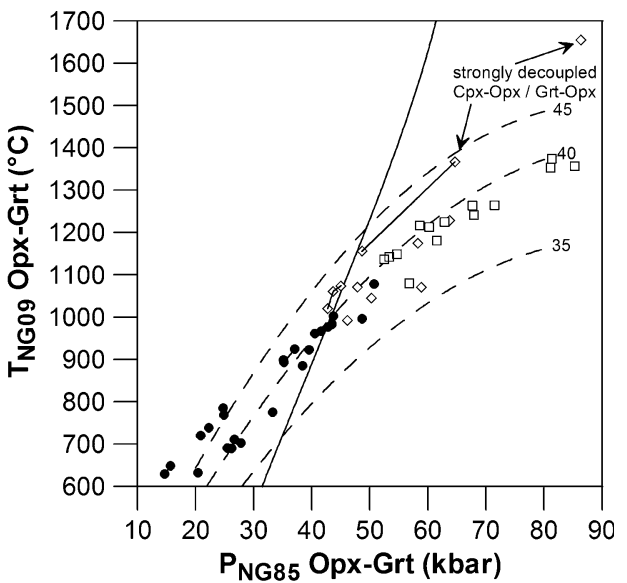

suggesting disequilibrium. Note that many harzburgitic samples, including the two graphite-bearing samples falling within the diamond field, could not be checked for equilibrium, owing to a lack of internally consistent alternative thermometers. Source of data for graphite- and diamond-bearing peridotites is given in the online Appendix. Only samples satisfying the quality criteria for orthopyroxene and garnet analyses adopted for the xenolith database were considered. The diamond-graphite boundary was calculated from thermodynamic properties of carbon from Chatterjee (1991) 